\title{
A Review of Social Theory for Teacher Education Research: Beyond the Technical- Rational by Kathleen Nolan \& Jennifer Tupper, J. (Eds.)
}

\author{
Douglas Brown and Lin Ge \\ University of Regina
}

Social theory has played a vital role in educational research. In the past, education research has drawn on an enormous volume of outstanding theoretical work contributing to education research. Nevertheless, much of this work adopts a theoretical focus and application that circumvents everyday practice, or the lived world of the teacher. Educational theorizing and practice, then, can remain distinctly separated. In this book, Nolan and Tupper ask how influential social theory can be more effectively associated with the educational practitioner (e.g., frontline teachers). Social Theory for Teacher Education Research: Beyond the Technical-Rational directly targets this rift in bolstering a more critical educational practice. The authors seek to access a rather broad theoretical literature, specifically as attending to effective educational practice. The objective is to transform, or at least mitigate, educational approaches that have remained somewhat aloof and instrumental. Arguably, then, this is not simply a challenge offered the theorist. The analyst must question a current obsession in preservice education to emphasize professional practice while in the process overlooking deeper structures and configurations of power. The authors survey this somewhat fractured landscape in a process of applying a theoretical interpretation to guided teacher research and discovery. The task is to assist the reader in critically rethinking this dividing line. This includes a reorganization of "technical-rational discourse" as an approach that hobbles education programs, teacher training, and the directed lifeworld of the professional. A central theme evolves here as existing teacher education programs and practices often emphasize professional standards, best practices, and prescribed measurements over academic insights and sociological explanations. The argument: Using social theory in teacher education research can promote deep-seated interpretations and conceptualized understanding of teaching practice.

This Tupper and Nolan edited book includes original case studies that further an understanding of the importance of social theory in the co-construction of knowledge in teacher education research. To achieve this the volume is divided into four distinct, yet thematically cohesive sections. Section 1 draws upon specific, historically applied, theoretical approaches. Included here are the extended logic of Barad and Deleuze, conceptually operating in a world of educational multiplicity. Bourdieu's field approach provides an alternative theoretical structure, critically reviewing the work of the teacher educator in creating responsible preservice educational environments. Section 2 discusses proactive teacher education programs and supports in the development of useful working technologies. Employed here are a myriad of pedagogical approaches and resources intended to address articulated classroom complexities at political, social, cultural, and historical levels. Section 3 asks the reader to consider alternative perspectives in guided field-based teacher education. Here one is asked to deeply reflect upon a teacher educator's identity, past, present, future. Drawing from Pinar's understanding of currere, experience becomes the medium of reflective analysis. Foucault enriches the theoretical field further in Section 3, introducing the metaphor of the panopticon. Employing Bentham's creation, one is introduced to complex ways in which the rules of social formation shape knowledge and truth and ultimately the lives of individuals. Section 4 directly targets the subject of teacher 
education. Drawing upon specific social theoretical frameworks the analyst theorizes both role and direction in teacher education.

Addressing each selection individually, the reader is treated to a rather eclectic and varied content, with theoretical approaches ranging both in terms of influence and extension. Here the residual influences of Weber are as at home as the discursive technologies of the post-structural thought. For example, in Chapter 4, Tupper and Nolan, exposed and analysed the "technicalrational" as the authors deconstruct power relations held within a specific educational field. Employing the writings of Bourdieu this article stresses the need for a more critical institutional approach to preservice teacher training, assisting teacher candidates in understanding and anatomizing current issues associate with a wider social and cultural context. The authors excavate the contested confluence of teaching and learning, stressing the need for an anti-oppressive education, effectively bolstering teacher candidates' critical thinking in cultivating active learners.

In Chapter 9 Sorensen acknowledges the deficits of humanism in the field experience of teacher education, as for the author, a differing theoretical exploration and refinement are required. Here new materialism and humanism serve to harness self-continuity and "indeterminacy" in teacher education, assembling a dynamic and interactive construction of knowledge, skills, and abilities. The work of the educational theorist Pinar is employed as reflective participants contemplate the past, analyze the present, and imagine the future.

For Chapter 10, Betts and Block draw from the extensive literature of Michel Foucault. Bentham's much-publicized model of the panopticons is employed, specifically in critiquing the ever-popular technique of performance-based measurement. Focusing upon what is described as the "success-failure binary" in teacher candidate practicums the authors seek to archeologically unearth discursive patterns in power/knowledge regimes. In this work educational discourses are named and critiqued, truth regimes occupying a discursive reality where all things are seemingly dangerous. Under the constant surveillance of the panopticon (Foucault, 1995), compliant bodies are surveyed and measured, with subject definition and identity synonymous with the language used in constructing the same. The authors, however, offer the reader a way out.

This collection covers disparate and contested theoretical literature. Underwriting this journey is the declared need to liberate education and educational analysis from tired and repetitious narratives which serve to ignore significant social processes. Social theory is neglected in teacher education. The text offers detailed and operable ways to advocate for change. The contributors are representative of institutions located in Canada, the United States, the UK, Australia, Brazil, and New Zealand. This volume, therefore, represents a collaborative body, international in scope, and is not constrained by social location. Arguably, contributors employ rich and varied theoretical approaches; however, sharing needed expertise in conjoining research with practice. Articles selected for this book appropriately pinpoint an editorial "focus on theory." Contributors draw upon a wide range of theoretical postures and theorists. Included here are Michel Foucault, Pierre Bourdieu, and Martin Heidegger. Addition contributors include Michel de Certeau, Basil Bernstein, and Bhashar. Importantly, the text facilitates a dialogue between relevant participants activating a deeper understanding and contextualized interpretation in teacher education.

Arguably, there is value here for the seasoned educator and neophyte alike, a toolkit for anyone interested in understanding teacher education research. Tupper and Nolan's selection recognizes the challenges and complexities associated with comprehending and critiquing 
educational processes. The authors argue for an application and understanding of social relations in education. They call for a critical response. Required are the adoption and deployment of different teaching approaches, technologies, and methodologies. For this, at least in part, we turn to theory, albeit cognizant of relevant social environments factors. There are lessons to be learned here if the reader is willing to listen. This collection asks us to rethink our deepest assumptions and biases concerning teaching and learning, particularly in educating the next generation of practitioners. This is an important request and one that should be heeded. Overtly managerial programs and processes make better cars than people. The choice is up to us. As Dewey (1995) so aptly articulates, there is nothing to which growth is related except more growth.

\section{References}

Foucault, M. (1995). Discipline and punish: The birth of the prison. Vintage Books.

Dewey, J. (1995). Education as growth. In R. Goodman (Ed.), Pragmatism a contemporary reader (pp. 93-101). Routledge. 